\title{
La Política entra als arxius o ICA-Atom i els arxius polítics
}

\section{Politics goes into the archives or ICA-Atom and the political parties archives}

\author{
Anna Nicolau Payàs \\ annipa09@gmail.com \\ Arxivera i documentalista \\ https://orcid.org/0000-0001-9681-9683
}

\section{Resum}

Les noves eines de gestió documental aporten molts avantatges per a l'organització i descripció dels fons d'arxiu i col·leccions. L'objectiu principal d'aquest article és presentar i analitzar el projecte d'organització i descripció de l'arxiu històric d'Unió Democràtica de Catalunya, posant especial atenció en la metodologia emprada i els resultats obtinguts. És a dir, el projecte de selecció i implementació d'un programari de gestió documental, l'ICA - AtoM, programari de codi lliure basat en la normativa internacional marcada pel Consell Internacional d'Arxiu (ICA), del qual s'expliquen les característiques i com s'ha adaptat a la complexa estructura orgànica i funcional d'un partit polític juntament amb les opcions que aporta pel que fa a la usabilitat i diferents vies de recuperació de la informació en el marc d'un sistema integrat de tots els recursos i eines a l'abast per a la recerca històrica.

\section{Paraules clau}

Arxius privats; Arxius polítics; Arxius històrics; Biblioteques especialitzades; Classificació; Instruments de descripció; Programari lliure; ICA - AtoM; Recuperació de la informació; Recursos integrats.

\begin{abstract}
The main objective of this paper is to present and analyse the experience of the description of the Archive of Unió Democràtica de Catalunya, paying particular attention to the methodology used and the results obtained. It explains the benefits that ICA - AtoM, a free open-source software and web-based archival description
\end{abstract}


software that is based on International Council on Archives (ICA) standard, offers to a corporation with a complex organical structure: the characteristics, multiple options of search and usability elements for an integrated system of information into finding aids. This archive and collections on political sciencies are appropriate for historical research.

\section{Keywords}

Private archives; Political parties archives; Historical archives; Special libraries; Classification; Finding Aids; Free open-source sofware; ICA - AtoM; Information retrieval systems; Integrated archives, Library and museums systems.

Recibido: 20/02/2018

Aceptado: 15/05/2018

DOI: http://dx.doi.org/10.5557/IIMEI9-N16-131165

Descripción propuesta: Nicolau Payàs, Anna, 2018. La Política entra als arxius o ICA-Atom i els arxius polítics. Métodos de Información, 9(16), 131-165.

\section{Introducció}

L'experiència que s'analitza en aquest article correspon a un aplicatiu creat amb aquest programari en una fundació que gestiona un arxiu polític. Els arxius polítics són uns grans desconeguts. Per tal de contextualitzar l'article, explicarem la dimensió que aquests poden representar i com ICA-Atom es pot adaptar a la seva naturalesa. És el resultat d'un projecte planificat pel qual calia un programari que permetés la descripció normalitzada del fons així com també donar accessibilitat al patrimoni de documentació sovint poc coneguda i que esdevé essencial, en aquest, cas per a l'estudi de la història política dels darrers vuitanta anys d'una organització privada que ha desenvolupat activitats en diversos àmbits $\mathrm{i}$ des de diferents perspectives, motiu pel qual té un indubtable valor històric. 


\section{L'arxiu d'Unió Democràtica de Catalunya}

La fundació INEHCA nascuda el 1992 ha estat la responsable de conservar, gestionar i difondre el fons d'Unió Democràtica de Catalunya des de la seva creació de 1996. L’Arxiu Històric Ferran Camps és el nom propi del fundador de l'arxiu privat i polític destinat a facilitar la consulta de la documentació tant interna als òrgans i militants del partit polític així com també orientat a atendre les consultes d'investigadors socials i al públic en general. Des de la seva creació ha tingut un lloc referencial i de suport a la tasca política continuada en diferents periodes fins a l'actualitat. És doncs aquesta experiència el cas que s'analitza. De la seva base de dades que ha estat activa fins el juliol de 2016 són les captures de pantalla que il·lustren l'article, concretament del seu mòdul d'administració.

És important considerar la gran i llarga trajectòria d'aquest partit polític que nascut durant la Segona República, el 1931, passà a formar part del govern des del 1980 i que aquest any ha complert el seu 85è aniversari. El fons conté la documentació generada per l'activitat d'UDC des del seus origens, en temps de la Segona República, fins a l'actualitat; si bé la documentació que es conserva en el seu arxiu històric és majoritàriament posterior a 1976. Les viscisituds de la història contemporània que ha protagonitzat però l'entitat han provocat que la documentació generada per organitzacions polítiques o sindicals romangui dispersa, fins i tot que s'hagi perdut, eliminat parcialment o bé que se n'hagi generat poca durant alguns periodes.

L'arxiu d'UDC està integrat tan pel fons corporatiu en totes les seves vessants de l'actuació política així com pel fons personals de militants que han tingut una participació activa al partit i també en la seva dimensió institucional. Conserva també una petita col·lecció de papers de partits polítics tant catalans com espanyols, d'abast europeu $i$ internacional, que aplega impresos $i$ documentació diversa aplegada en la seva trajectòria tals com publicitat electoral, ponències, notícies, candidatures, programa, proclames, manifestos, etc.

Es presenta a continuació un esquema del seu quadre de classificació per tal de poder advertir la dimensió política i complexa estructura: 
G100 Documents constitutius $i$ règim intern

G120 Coordinació administrativa

G121 Planificació i organització

G122 Funcionament i gestió interna

G123 Estructura orgànica

G126 Direcció del partit

G133 Desplegament territorial

G134 Desplegament sectorial

G140 Atenció a col·lectius concrets (equips especialitzats)

G160 Legislació $i$ assumptes jurídics

G170 Gestió dels recursos humans

G190 Gestió econòmica

G270 Gestió de béns mobles $i$ immobles

G280 Gestió dels recursos d'informació

G330 Gestió de les publicacions

G340 Comunicació i gestió pública

G500 Entitats polítiques vinculades

E100 Acció de govern a les institucions

E101 Actuació política institucional

E120 Activitat legislativa

E200 Referèndums i eleccions: participació política

E270 Gestió dels serveis oferts als afiliats

E290 Qüestions doctrinals

E300 Celebracions $i$ actes civics

E310 Dossiers de premsa

\section{Projecte d'automatització de l'arxiu}

El 2013 es parteix d'un arxiu en paper reunit per personal col·laborador afí al partit polític que havia iniciat la tasca de captació de documentació a mans privades d'antics militants o dirigents als anys norantes si bé feia molts anys que no tenia ningú assignat per a la seva organització i manteniment. Hi havia un esquema o quadre però no es corresponia amb l'ordenació i documentació per processar. La manca d'operativitat d'una antiga base de dades evidenciava i feia més imminent la necessitat de disposar d'una eina tecnològica a l'hora de localitzar la documentació i com a mesura de seguretat, més encara tenint en compte els dos trasllats de la seva seu principal en la seva vida activa i la multiplicitat de seus al territori.

La informació de referència per a localitzar la informació consistia en: 


\section{DESCRIPCIÓ}

1.1. Llistat d'inventaris d'alguns fons personals en format Word (parcial).

1.2. Descripció parcial de la sèrie dels "Equips especialitzats".

1.3. Documentació diversa estructurada per suports d'origen.

\section{RECURSOS DE GESTIÓ}

2.1. Base de dades en Access de contactes.

2.2. Llistat en excel de publicacions periòdiques.

El fons corporatiu està format per un arxiu de documents textuals, gràfics, sonors $i$ audiovisuals, en paper i digitals, $i$ també per un fons bibliogràfic de llibres, revistes, reculls de premsa $\mathrm{i}$ un arxiu temàtic amb documentació diversa; és a dir pel fons documental i el centre de documentació amb recursos propis i especialitzats en política, ciències socials i història. La seva implementació estava prevista en tres fases:

1) Tractament de la documentació física.

2) Tractament de la documentació en suport electrònic (s'ha recuperat un volum considerable de documentació guardada en suports òptics i d'altra als servidors corporatius).

3) Control i gestió de les transferències.

Per aquest motiu, ja d'entrada, l'opció escollida havia de permetre allotjar fitxers electrònics i associar-los a les descripcions (d'origen o bé les versions digitalitzades d'alguns dels documents) per a la seva sortida web.

Integrar en una mateixa base de dades documentació en diferents suports $i$ tipologies requeria, per tant, un programari flexible i que reproduís, d'una banda, els procediments o processos de l'organització i que, per altra banda, servís de base per si en un futur es volia implementar un sistema de gestió documental, a partir del qual poder aplicar un calendari de conservació juntament amb el quadre de permisos. Es va optar per un quadre de classificació funcional; existia un esquema previ de quadre de classificació resultat d'una anterior intervenció arxivística el 2004 i aplicat només a una petita part de la documentació: el criteri primer fou cronològic i després orgànic si bé la descripció era molt parcial, fragmentària i general, descrita en fitxers de text o manuscrits. 
La intenció inicial de la Fundació era poder donar resposta a les consultes internes i externes i donar visibilitat a l'arxiu: la difusió de la documentació més històrica oberta a la xarxa així com a la vegada poder oferir-ne una guia. La prioritat doncs es centrà en l'avaluació de sistemes a partir de les llurs possibilitats pel que fa al disseny i a les prestacions ofertes que permetessin desenvolupar una plataforma digital àgil d'utilitzar per a una gestió interna més fluïda que es pogués implementar de manera progressiva.

D'entrada, no existia cap condicionament a l'hora de proposar una eina informàtica amb la qual ser compatible. El fet que es comptés amb el treball i suport d'un departament informàtic portà a decidir-nos per un programari lliure. Si bé les característiques que comparteixen els sistemes de gestió bibliotecària optimitzats per tal de poder gestionar bases de dades bibliogràfiques no permetien assumir una integració total del material imprès amb el material d'arxiu pel que fa a donar-los context. Les eines analitzades foren PMB, Koha i OpenBiblio. Les funcionalitats d'alguna manera afins tant a les necessitats d'un arxiu com a les d'una biblioteca són:

- Catàleg integrat on descriure diferents tipologies documentals;

- Administrar el sistema amb cert grau de personalització;

- Instal-lar un aplicatiu de forma local en un equip, restringir l'accés a una xarxa interna, o bé un repositori digital d'accés a través d'internet o al núvol.

- Gestió de contenidors o registres d'exemplar;

- Reutilització de la informació: de recursos externs per mitjà del protocol Z39.50 (biblioteques) i dels propis recursos (interns en el cas d'increments de fons i pel principi de procedència);

- Importació i exportació de registres i, entre d’altres,

- Interfície web i gestió d'estadístiques o extracció de llistats per a la difusió selectiva de la informació i força possibilitats d'explotació.

- Gestió d'usuaris, si bé en el cas de la documentació d'arxius cal que els rols es defineixen de manera més diferencial i exclusiva per temes de protecció de dades d'una major complexitat.

- Ús de taxonomies i llistats controlats (en alguns casos).

- Possibilitat de crear instruments de descripció compartits. 
Les diferències que presentava la documentació d'arxiu féu però centrar l'atenció en la necessitat de donar context a les descripcions de manera clara amb una presentació a més d'un nivell, tant jeràrquicament parlant com de dipòsits. Alguns dels requisits que havia d'acomplir són:

- Formats: MARC21 (àmbit bibliotecari i de centres de documentació) versus $\mathrm{EAD}$ (àmbit arxivístic).

- Classificació: és un camp del registre o fitxa descriptiva pel qual es pot ordenar el resultat d'una cerca i que, a més a més, pot formar part de l'estructura d'un sistema dinàmic o funcional.

- Nivells de descripció: descripció d'unitats documentals simples (col·leccions de documents) i la possibilitat a més de descriure unitats documentals compostes i col·leccions de documents (multinivell).

La voluntat d'establir vincles i referències internes entre les descripcions doncs excloïa els sistemes de gestió de colleccions digitals destinats a agrupar recursos electrònics, amb categories classificatòries, però al mateix nivell, en les quals s'agrupen: si bé permeten diferents sistemes de cerca es basen pràcticament en text lliure $\mathrm{i}$ funcionen més aviat com a agregadors de contingut o repositori web organitzat. No haguessin donat cabuda aleshores a la documentació en suport físic no digitalitzada i ens calia un sistema de gestió documental que organitzés la documentació per procedència i que alhora fos amigable.

En relació amb els expedients, era convenient que el programari escollit pogués desenvolupar algunes tasques més pròpies dels sistemes de gestió documental:

- Dipòsit de documents electrònics en format original (en una segona fase).

- Classificació de documents.

- Cercador de documents i del seu contingut.

- Diferents nivells de accés. 
No obstant, els trets que els són més definitoris són l'ingrés dels documents en el moment de ser generats, la gestió de regles de contingut, dels fluxes de treball en tot el seu cicle, control de versions, edició de documents i la de transformar els formats de forma automàtica; per tant, sobretot de documents electrònics si bé cal que contemplin la documentació en paper i els expedients híbrids.

La perspectiva d'implementar un projecte integral en aquest sentit no es preveia a curt termini donada la complexitat de l'estructura corporativa i tenint en compte el canvi en la cultura organitzativa que implicava. Calia però contemplar aquesta possibilitat cas en què seria necessari la compatibilitat entre un sistema d'aquestes característiques i la integració dels documents en un sistema de gestió de bases de dades documental per a ser consultat i preservats des d'aquesta aplicació.

\section{Selecció del programari}

Ja més en l'àmbit dels arxius, abans s'ha fet recerca d'experiències similars en l'àmbit nacional $\mathrm{i}$ internacional per tenir unes referències per engegar el projecte de difusió.

En el procés s'han avaluat programaris i també experiències concretes que els han implementat: ICA-Atom (Artefactual Systems, 2013), Archivist'sToolkit (ATUG-I, 2013), Archon (University of Illinois, 2013). A continuació es comparen en una taula on es detallen les principals característiques (Moreiro, J.A. et al., 2012) ${ }^{1}$ :

\begin{tabular}{|c|c|c|c|c|}
\hline & Requisits & Archon & $\begin{array}{l}\text { Archivists'Toolk } \\
\text { it }\end{array}$ & ICA-AtoM \\
\hline $\begin{array}{l}\text { Descripció } \\
\text { arxivística }\end{array}$ & $\begin{array}{l}\text { Ús de } \\
\text { normatives } \\
\text { internacionals } \\
\text { de descripció } \\
\text { d'arxius } \\
\text { ISAD }(G) \text { i es } \\
\text { poden crear per } \\
\text { a diferents }\end{array}$ & $\begin{array}{l}\text { Estàndards } \\
\text { internacional } \\
\text { s de } \\
\text { descripció: } \\
\text { ISAD (G), } \\
\text { ISAAR } \\
\text { (CPF), ICA- } \\
\text { ISDIAH, }\end{array}$ & & $\begin{array}{l}\text { Estàndards } \\
\text { internacionals } \\
\text { de descripció: } \\
\text { ISAD (G), } \\
\text { ISAAR (CPF), } \\
\text { ICA-ISDIAH, } \\
\text { ISDF, RAD }\end{array}$ \\
\hline
\end{tabular}

${ }^{1} \mathrm{~S}$ 'ha actualitzat la informació obtinguda d'aquest article. 


\begin{tabular}{|c|c|c|c|c|}
\hline & grups d'usuaris & ISDF, RAD & & \\
\hline Consulta & $\begin{array}{l}\text { Opcions de } \\
\text { cerca }\end{array}$ & $\begin{array}{l}\text { Cerca } \\
\text { simple, } \\
\text { avançada, } \\
\text { índexs } \\
\text { navegació) }\end{array}$ & $\begin{array}{l}\text { (adaptació dels } \\
\text { camps de cerca) }\end{array}$ & $\begin{array}{l}\text { (Cerca simple, } \\
\text { avançada, } \\
\text { índexs } \\
\text { navegació) }\end{array}$ \\
\hline $\begin{array}{ll}\text { Quadres } & \text { de } \\
\text { classificació } & \end{array}$ & $\begin{array}{l}\text { Descripció } \\
\text { multinivell }\end{array}$ & $\begin{array}{l}\text { (codificació } \\
\text { descriptiva) }\end{array}$ & & $\begin{array}{l}\text { (codificació } \\
\text { del quadre de } \\
\text { classificació i } \\
\text { codi de } \\
\text { referència } \\
\text { acumulatiu) }\end{array}$ \\
\hline Préstec & $\begin{array}{l}\text { Gestió, control } \\
\text { i devolució }\end{array}$ & & & \\
\hline Impressió & $\begin{array}{l}\text { Generació } \\
\text { d'etiquetes o } \\
\text { informes de les } \\
\text { consultes }\end{array}$ & & & $\begin{array}{l}\text { Impressió } \\
\text { d'informes } \\
\text { (no es poden } \\
\text { guardar } \\
\text { cerques) }\end{array}$ \\
\hline Gestió d'usuaris & $\begin{array}{l}\text { Definició de } \\
\text { grups d'usuaris } \\
\text { amb diferents } \\
\text { drets d'accés a } \\
\text { funcions } \quad \text { i } \\
\text { informació }\end{array}$ & & & $\begin{array}{l}\text { (més } \\
\text { funcionalitats } \\
\text { en definir rols) }\end{array}$ \\
\hline Transferències & $\begin{array}{l}\text { Control i avís } \\
\text { de l'arxiu de } \\
\text { gestió a l'arxiu } \\
\text { central i llistat } \\
\text { d'ingressos } \\
\text { (mòdul } \\
\text { d'ingressos) }\end{array}$ & & & \\
\hline $\begin{array}{ll}\text { Gestió } & \text { de } \\
\text { dipòsits } & \end{array}$ & $\begin{array}{l}\text { Ubicacions } \\
\text { diferents de la } \\
\text { documentació } \\
\text { per a clicar }\end{array}$ & & $\begin{array}{l}\text { (ubicació física i } \\
\text { mida) }\end{array}$ & $\begin{array}{l}\text { (guarda } \\
\text { etiquetes) }\end{array}$ \\
\hline $\begin{array}{l}\text { Explotació } \\
\text { estadística }\end{array}$ & $\begin{array}{l}\text { Generació } \\
\text { automàtica }\end{array}$ & & & (previst) \\
\hline
\end{tabular}




\begin{tabular}{|c|c|c|c|c|}
\hline & $\begin{array}{l}\text { d'estadístiques } \\
\text { de transf. , } \\
\text { préstec, volum } \\
\text { de dod. } \\
\text { gestionada. Etc. }\end{array}$ & & & \\
\hline $\begin{array}{lr}\text { Calendari } & \text { de } \\
\text { conservació } & / \\
\text { sèries } & \\
\text { documentals } & \end{array}$ & $\begin{array}{l}\text { Condicions } \\
\text { d'accés per a } \\
\text { cada doc. o exp. } \\
\text { I un termini de } \\
\text { conservació }\end{array}$ & & & \\
\hline $\begin{array}{ll}\text { Gestió } & \text { de } \\
\text { documents } & \\
\text { electrònics } & \end{array}$ & $\begin{array}{l}\text { Descripció de } \\
\text { documents pot } \\
\text { incloure } \\
\text { l'objecte digital }\end{array}$ & $\begin{array}{l}\text { (pujar fitxers } \\
\text { i enllaços) }\end{array}$ & & $\begin{array}{l}\text { (pot incloure } \\
\text { la reproducció } \\
\text { de material } \\
\text { multimèdia) }\end{array}$ \\
\hline $\begin{array}{l}\text { Emmagatzematg } \\
\mathrm{e}\end{array}$ & $\begin{array}{l}\text { Possibilitat } \\
\text { d'emmagatzema } \\
\text { r i consultar les } \\
\text { metadades de } \\
\text { cada registre }\end{array}$ & & & \\
\hline $\begin{array}{l}\text { Documentació } \\
\text { de suport }\end{array}$ & $\begin{array}{l}\text { Qualitat de la } \\
\text { plataforma de } \\
\text { suport, } \\
\text { manteniment, i } \\
\text { comunitat } \\
\text { d'usuaris }\end{array}$ & $\begin{array}{l}\text { (poc } \\
\text { detallada } \\
\text { però } \\
\text { actualitzada) }\end{array}$ & $\begin{array}{lr}\text { extensa } & \text { i } \\
\text { detallada } & \text { no } \\
\text { actualitzada) } & \end{array}$ & $\begin{array}{l}\text { (wiki amb } \\
\text { informació } \\
\text { poc detallada } \\
\text { però } \\
\text { actualitzada) }\end{array}$ \\
\hline \multicolumn{5}{|l|}{$\begin{array}{l}\text { Afegir adreces de } \\
\text { contacte }\end{array}$} \\
\hline $\begin{array}{l}\text { Llistats } \\
\text { controlats } \\
\text { d'autoritats }\end{array}$ & $\begin{array}{l}\text { Flexibilitat en } \\
\text { poder } \\
\text { implementar } \\
\text { llenguatges } \\
\text { documentals } \\
\text { preexistents o } \\
\text { nous }\end{array}$ & $\begin{array}{l}\text { (en entrar els } \\
\text { descriptors } \\
\text { cal } \\
\text { seleccionar la } \\
\text { tipologia de } \\
\text { matèria: } \\
\text { nom, } \\
\text { geogràfic, } \\
\text { tema, gènere } \\
\text {-tipus de } \\
\text { documents-, } \\
\text { etc.) }\end{array}$ & & $\begin{array}{l}\text { (recomanat el } \\
\text { tesaurus de la } \\
\text { Unesco per a } \\
\text { matèries de } \\
\text { tema) } \\
\text { (els índexs } \\
\text { dels } \\
\text { descriptors es } \\
\text { poden } \\
\text { consultar } \\
\text { jeràrquicamen } \\
\text { t) }\end{array}$ \\
\hline
\end{tabular}




\begin{tabular}{|c|c|c|c|c|}
\hline Repositoris & $\begin{array}{l}\text { Opció de } \\
\text { sistemes } \\
\text { multirepositori }\end{array}$ & & & \\
\hline $\begin{array}{l}\text { Manteniment } \\
\text { (data darrera } \\
\text { actualització) }\end{array}$ & & $\begin{array}{l}2014 \\
\text { (substituït } \\
\text { per } \\
\text { ArchiveSpac } \\
\text { e: LYRASIS, } \\
\text { 2017) }\end{array}$ & $\begin{array}{l}2013 \\
\text { (substituït per } \\
\text { ArchiveSpace) }\end{array}$ & $\begin{array}{l}2015 \\
\text { (migrat a } \\
\text { Archivematica } \\
\text { i Atom) }\end{array}$ \\
\hline $\begin{array}{l}\text { Metadades i } \\
\text { formats } \\
\text { d'exportació }\end{array}$ & & $\begin{array}{l}\text { MARC, } \\
\text { EAD (XML) } \\
\text { o CSV }\end{array}$ & $\begin{array}{l}\text { EAD } \quad(\text { XML), } \\
\text { MARC, } \quad \text { METS, } \\
\text { MODS i DC }\end{array}$ & $\begin{array}{l}\text { EAD (XML), } \\
\text { CSV, DC i } \\
\text { plugins [amb } \\
\text { Archivematica } \\
\text { també altres } \\
\text { de preservació } \\
\text { digital: METS, } \\
\text { PREMIS i } \\
\text { DC] }\end{array}$ \\
\hline
\end{tabular}

\section{Introducció a ICA-AtoM}

El programari lliure ICA-AtoM web de codi obert per a arxius ha anat guanyant terreny en la gestió dels arxius històrics. Desenvolupat per l'empresa canadenca Artefactual Systems, ha estat impulsat pel grup de treball Arxius i Drets Humans de l'International Council for Archives com el seu nom indica, apareix a l'escena arxivística cap a 2007 amb la intenció de difondre l'ús dels estàndards $\mathrm{i}$ normatives internacionals en el sector per a fer accessible la memòria històrica a la societat (Acces to Memory). L'ús de la tecnologia Atom el fa òptim per a descriure arxius ja que que s'adapta a les seves característiques intrínseques com són la descripció multinivell, heretabilitat de dades com el codi de referència, el productor i la institució arxivística, multilingüe, l'ús d'índex normalitzats, taxonomies, extracció de llistats, múltiples punts d'accés i opcions de cerca de la informació entre d'altres que s'aniran comentant a la pràctica. Molt interessant referir el servei ofert per l'Escola Superior d'Arxivística i Gestió de Documents de Catalunya (Esaged) junt amb l'empresa Serivicio Móvil sota el nom de Molècula projecte dissenyat 
com a aplicació integral que ofereix el seu servei també com de repositori i gestor de transferències documentals ${ }^{2}$.

Es tracta d'un programari lliure elaborat per la Unesco per encàrrec de l'agència internacional de normalització en l'àmbit dels arxius i en col-laboració amb la National School for Archivists d'Holanda i gestionat actualment per una empresa de consultoria anomenada Art Factual Systems. El fet que l'Associació d'Arxivers de Catalunya hagi donat suport a l'ICAAtoM (ara Atom) en el desenvolupament de la plataforma Molècula ha estat un punt a favor.

Els avantatges i funcionalitats que aporta de cara al projecte són:

o Disposar d'una versió demo per a conèixer millor l'eina a més de la llista d'institucions que l'han implementat.

o Seguir la normativa internacional arxivística i és recomanat per institucions internacionals i de l'Esaged.

o Descripció multinivell: de la més general del fons a la més específica de cada document.

o Gestió de descripcions de documents físics i també adjuntar documents electrònics.

o Relació entre les descripcions.

o Funcionar en xarxa (incloure fons de més d'una institució arxivística; s'hi podrien considerar les delegacions territorials, per exemple o entitats relacionades).

o Descripció de més d'un fons d'arxiu i de cadascun permet fer una fitxa descriptiva general que encapçala la descripció dels documents que conté.

o Aplicar les normes de conservació i d'accés.

o Gestió dels ingressos o transferències.

o Gestió de més d'un dipòsit (físic o digital).

o Difusió web.

${ }^{2} \mathrm{El}$ suport professional i desenvolupament de l'eina està assegurat amb el projecte MOLĖCUlA (Escola D'ARXivística i Gestió DE Documents DE CATALunya i SERVICIO MÓVIL, 2013). 
o Treball amb llistats normalitzats de noms, matèries i llocs (quan s'introdueixen els termes es conserven com a menú per tal de no duplicar les entrades, que s'entrin sempre igual i que es pugui recuperar de manera més efectiva i fiable).

o Identificació de la documentació sempre visible a la capçalera en pantalla.

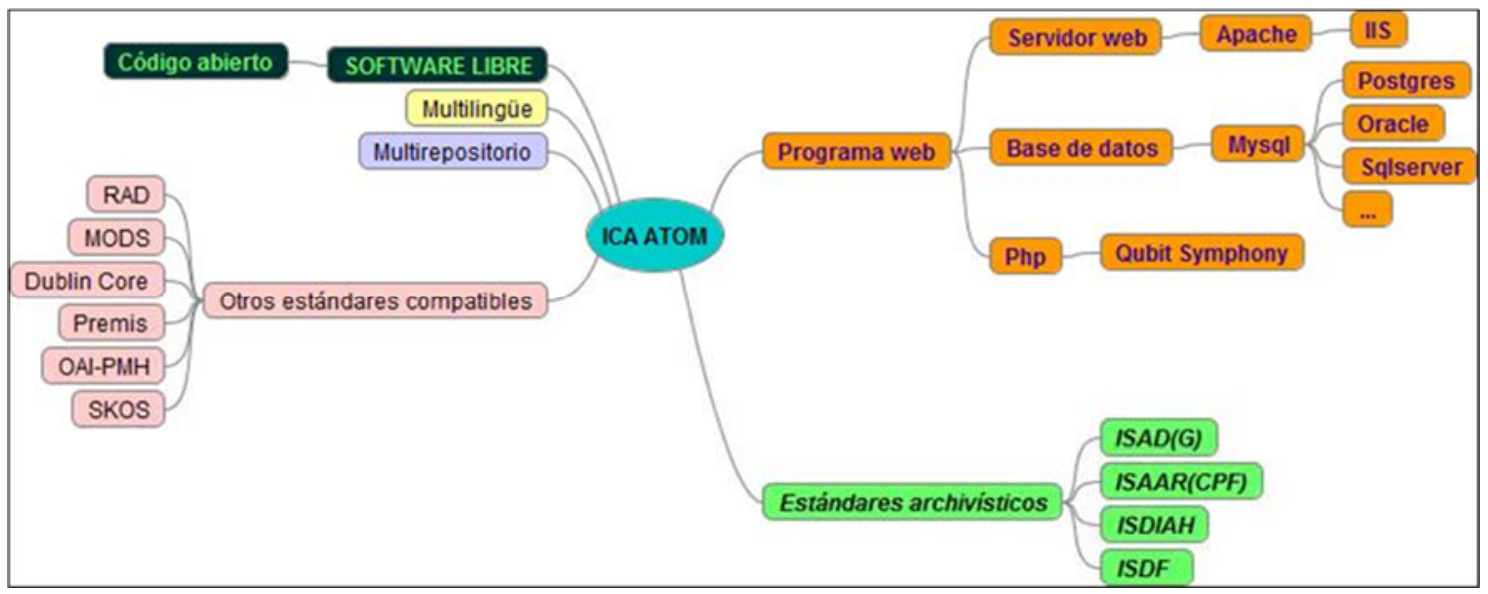

Figura 0: Estructura del sistema ICA-Atom (Temesio, S., 2014).

Les característiques dels tres programaris examinats eren bastants similars si bé es prioritzà, en l'elecció, el suport i manteniment de la plataforma d'ICAAtom així com també els elements que es comenten al llarg de l'article. A més, donat que no es partia de cap base de dades per a la biblioteca existent, el format MARC no era imprescindible i, a més, encara que el llenguatge de metadades DUBLIN CORE no permet tants matisos ni té una exacta correspondència amb $\operatorname{ISAD}(G)$ és molt utilitzat a nivell internacional i per tant el fa molt apte per a compatibilitzar amb altres aplicacions com, per exemple, Alfresco o repositoris com Archive Space, així com també li confereix més opcions de ser recuperable pels cercadors a internet i de format part a través d'agregadors de múltiples plataformes multiplicant així les vies d'accés per al públic investigador a través del protocol d'intercanvi de dades OAI-PHH.

\section{ICA-Atom i els arxius polítics}

Els arxius polítics són arxius privats que gestionen documentació de diferent tipologia. Les múltiples funcions que duen a terme els fa potencialment susceptibles de ser tractats des de diferents punts de vista. Si bé l'instrument 
de descripció en què es centra l'article no s'ha pogut desenvolupar en la seva totalitat, a partir d'algunes funcionalitats anirem concretant els avantatges $i$ potencial que aporta:

\section{Un o més arxius?}

o Figura de les "institucions arxivístiques".

0 Estructura jeràrquica i facetada.

o Possibilitat d'integrar diversos fons.

o Flexibilitat i transversalitat.

o Catàleg integrat de recursos.

\subsection{Figura de les "institucions arxivístiques".}

En primer lloc, destaquem que aquest programari ofereix la possibilitat de confeccionar un repertori de recursos documentals pertanyents a una única institució o entitat arxivística entesa com a sistema d'informació que gestiona i custodia un/més arxiu/s, i també diversos centres que poden treballar en un mateix entorn però amb un "espai" propi identificat i accessible de manera convenientment diferenciada. Aquest avantatge però es pot adoptar cenyint-se a casuístiques concretes com es planteja a continuació.

L'opció triada ha estat la de considerar dues "institucions" o "dipòsits" diferenciades dins del mateix servei ubicades ambdues a la seu nacional de l'entitat: l'arxiu central i el centre de documentació especialitzat en democràcia cristiana, ciències socials i polítiques i cultura catalana. Per tant, documentació d'arxiu i material bibliogràfic descrits $i$ gestionats en una mateixa eina. No obstant es poden considerar com a alternatives algunes pràctiques igualment possibles i vàlides en un context similar.

Com a alternativa, es podrien també considerar com a "institucions arxivístiques" les diferents localitzacions de les delegacions del Partit en el supòsit d'un arxiu descentralitzat, per les fundacions vinculades al Partit en cas de ser actives i tenir diferent naturalesa jurídica i/o seu, o bé la documentació generada per la seva actuació en el si de les institucions públiques per mitjà dels seus diputats (grups parlamentaris), càrrecs de govern (grups municipals o consellers) o alts càrrecs públics en organismes públics: Catalunya, Madrid i 
Europa, per exemple, atenent a diverses seus on es generen documents i a diferents sèries del quadre de classificació.

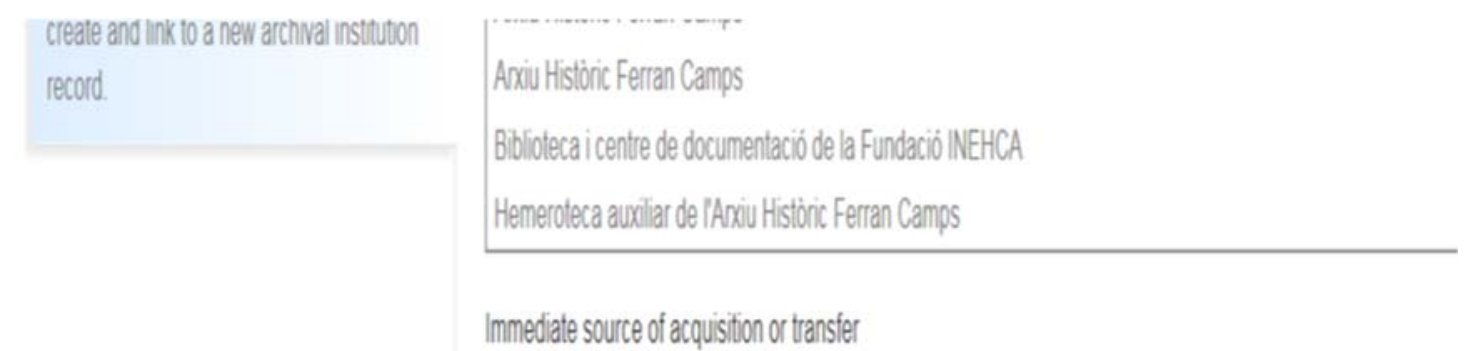

Figura 1: Nom de les institucions arxivístiques donades d'alta al camp "Repository"

\subsection{Estructura jeràrquica i facetada.}

L'anàlisi de l'estructura orgànica i funcional d'Unió Democràtica de Catalunya és essencial i complexa. Pot tenir quatre lectures:

6.2.1 Estructura orgànico-funcional del quadre de clasificació en tant que organisme privat, amb classes $i$ sèries específiques corresponents a les funcions que li són pròpies. És possible la navegació pel quadre que es pot amagar o desplegar.

7 Fons UDC - Fons Unió Democràtica de C

v Subfons AG - Fons general dUnió Democ.

- Grup de sèries G100 - DOCUMENTS C.

- Sèrie G101 - Precedents d'Unió Democr.

- Sèrie G102 - Constitució

- Grup de sèries G120 - COORDINACIÓ I.

- Grup de sèries G160 - LEGISLACIÓIA.

- Sèrie G128 - POSICIONAMENT POLÍTIC

- Grup de sèries G170 - GESTIÓ DELS R.

- Grup de sèries G190 - GESTIÓ ECONÓ.

- Grup de sèries G270 - GESTIÓ DE BÉ..

- Grup de sèries G280 - GESTIÓ DELS R.

v Grup de sèries G330 - GESTIÓ DE LES... ミ

- Grup de sèries G340 - COMUNICACIÓ.

- Grup de sèries G500 - ENTITATS POLí.

- Grup de sèries E100 - PARTICIPACIÓ.

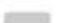

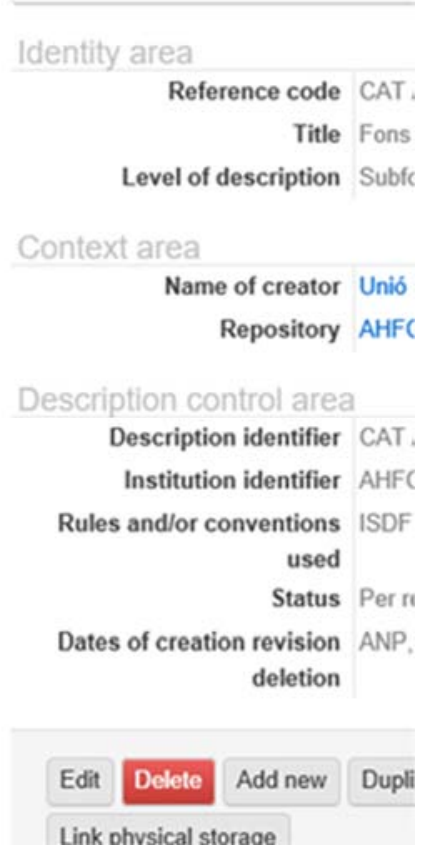

Figura 2: Quadre de classificació del Fons Unió Democràtica de Catalunya 
6.2.2 Existència d'entitats vinculades amb naturalesa jurídica pròpia, una d'elles, INEHCA:

\section{G500 Entitats politiques vinculades \\ G501 Fundació INEHCA \\ G580 Fundació Dr. Lluís Vila d’Abadal}

A partir del principi de procèdencia, es va optar per considerar cadascuna d'elles com a subfons però integrades en el mateix quadre. El motiu: en el primer segon cas, estava dissolta en el moment d'iniciar el projecte arxivístic d'inventari i, en el primer, la forta vinculació entre ambdues i les circumstàncies que es donaren pel que fa a la gestió de l'Arxiu. El canvi de context ha comportat separar la documentació -físicament ja diferenciada- i considerar l'extracte del quadre com a fons independent. Ambdues pràctiques es consideren, per separat, tècnicament vàlides.

6.2.3 La documentació relativa a la coalició Convergència i Unió s'ha integrat al fons de dues maneres. Per una banda, amb dues sèries cronològicament consecutives per les tasques derivades de la funció electoral i institucional que s'han desenvolupat durant molts anys conjuntament (la documentació generada independentment és anterior a 1978 (coalició), 2001 (federació) i posterior a 2015. Per altra banda, hi ha les sèries exclusives que s'han agrupat de forma diferenciada sota la subclasse titulada "COMUNICACIÓ AMB LA COALICIÓ/FEDERACIÓ”:

\begin{tabular}{|c|c|c|c|c|}
\hline G361 & 03 & Notes i comunicats de premsa de la coalició & Subsèrie 2 & Àmbit/secció \\
\hline G372 & & Comunicació amb la coalició / federació & subSèrie 1 & $\begin{array}{l}\text { Àmbit/Secció } \\
\text { activitat }\end{array}$ \\
\hline G372 & 01 & $\begin{array}{l}\text { Repartiment de les llistes als governs } \\
\text { municipals }\end{array}$ & Subsèrie 2 & Àmbit/Secció \\
\hline G372 & 02 & $\begin{array}{l}\text { Repartiment de les llistes al govern de la } \\
\text { Generalitat }\end{array}$ & Subsèrie 2 & Àmbit/Secció \\
\hline G372 & 03 & $\begin{array}{l}\text { Repartiment de les llistes al govern del } \\
\text { govern central }\end{array}$ & Subsèrie 2 & Àmbit/Secció \\
\hline G372 & 04 & Bases per a les relacions UDC-CDC & Subsèrie 2 & Àmbit/Secció \\
\hline
\end{tabular}




\begin{tabular}{|c|c|c|c|c|}
\hline G372 & 05 & $\begin{array}{l}\text { Convocatòries } \mathrm{i} \text { actes de les reunions entre } \\
\text { UDC-CDC }\end{array}$ & Subsèrie 2 & Àmbit/Secció \\
\hline G372 & 06 & $\begin{array}{l}\text { Convocatòries i actes de les reunions del } \\
\text { Comitè d'Enllaç de CIU }\end{array}$ & Subsèrie 2 & Àmbit/Secció \\
\hline G372 & 06 & Correspondència enviada a CDC & Subsèrie 2 & Àmbit/Secció \\
\hline G372 & 07 & Correspondència rebuda per UDC & Subsèrie 2 & Àmbit/Secció \\
\hline G372 & 08 & Correspondència electoral enviada de CIU & Subsèrie 2 & Àmbit/Secció \\
\hline
\end{tabular}

6.2.4 Els equips especialitzats des dels seus inicis reconeguts en els estatuts d'UDC es consideren com a unitats especialitzades adreçades a diferents col-lectius creades pel Consell Nacional, òrgan directiu del partit 0 . A més de tasques de suport electoral sobretot $\mathrm{i}$ activitats organitzades conjuntament presenten una estructura i funcionament paral·lels ja que tenen els seus propis: estatuts, reglaments, manifestos, etc. La seva vinculació amb el partit és forta ja que cadascun d'ells té representació dins de totes les delegacions territorials i, a la vegada, pot tenir comissions pròpies sobre diverses temàtiques. No obstant, gaudeixen de certa autonomia. És per això que s'han integrat també en el mateix quadre de classificació com a subfons.

\section{G120 Coordinació administrativa}

G140 Atenció a col·lectius concrets (equips especialitzats)

G141 Joves

G142 Dones

G143 Treballadors

G144 Gent Gran

G145 Unió Municipal

G146 Unió de Famílies ${ }^{3}$

\footnotetext{
${ }^{3}$ És una fundació no vigent però s'ha inclòs en aquest apartat atenint-nos a la similitud quant a funcions $i$ àmbit.
} 


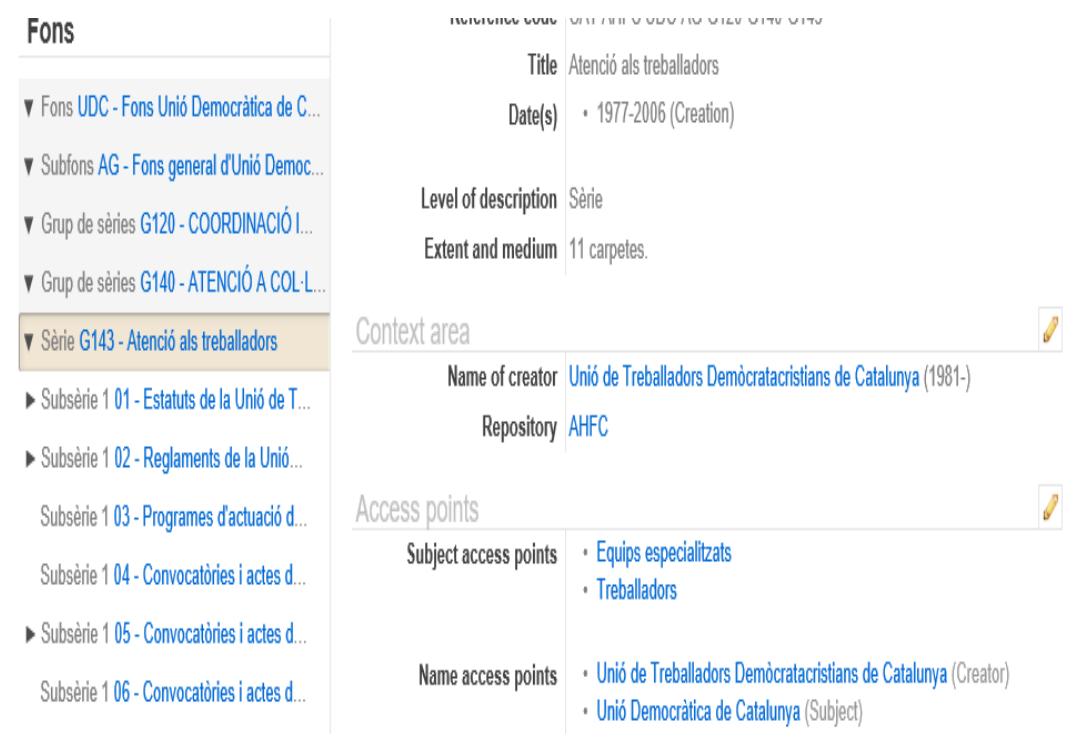

Figura 3: Extracte amb les sèries de la Unió de Treballadors Demòcrata Cristians (UTDC)

6.2.5 Doble dimensió de l'arxiu corporatiu d'UDC des del punt de vista territorial i sectorial, és a dir:

ESTRUCTURA TERRITORIAL en tres nivells jeràrquics: el nacional (òrgans administratius i directius), intercomarcal (Barcelona Ciutat, Barcelona Comarques, Girona, Lleida, Tarragona, Terres de l'Ebre), comarcal (comarques) i local (d'un o més municipis). En aquest sentit es constitueixen com a unitats orgàniques de suport en els respectius territoris.

\section{G120 Coordinació administrativa}

\section{G133 Desplegament territorial}

ESTRUCTURA SECTORIAL en diferents àmbits d'actuació política que afecta tota la vida social, política i cultural: Sanitat, Educació, Cultura, Mitjans de Comunicació, Seguretat civil, Economia i Finances, Benestar social, Esports, etc. En aquest sentit es constitueixen com a unitats orgàniques de suport especialitzades en les respectives matèries:

\section{G120 Coordinació administrativa}

G134 Desplegament sectorial 
Com a llenguatge documental per a la indexació, s'ha adaptat respectivament un llenguatge documental postcoordinat $i$, traduït al català, un tesaurus multidisciplinar d'ús internacional: LEMAC (BIBLIOTECA DE CATALUNYA, 2009) i el Tesauro de la Unesco (Unesco, 1977). S'ha tingut també com a referència la terminologia emprada per l'entitat en el seus documents constitutius i aquells que han regit la seva vida política: estatuts, reglaments, etc.

En resum, la classificació de la documentació generada en aquests casos ha estat també el d'integrar-la en el mateix quadre amb subdivisions orgàniques sota cada sèrie de l'arxiu corporatiu. És l'opció triada per ser la més idònia quan es tracta d'unitats orgàniques amb funcions comunes i paral·leles entre si (són orgànicament extensions del Partit).

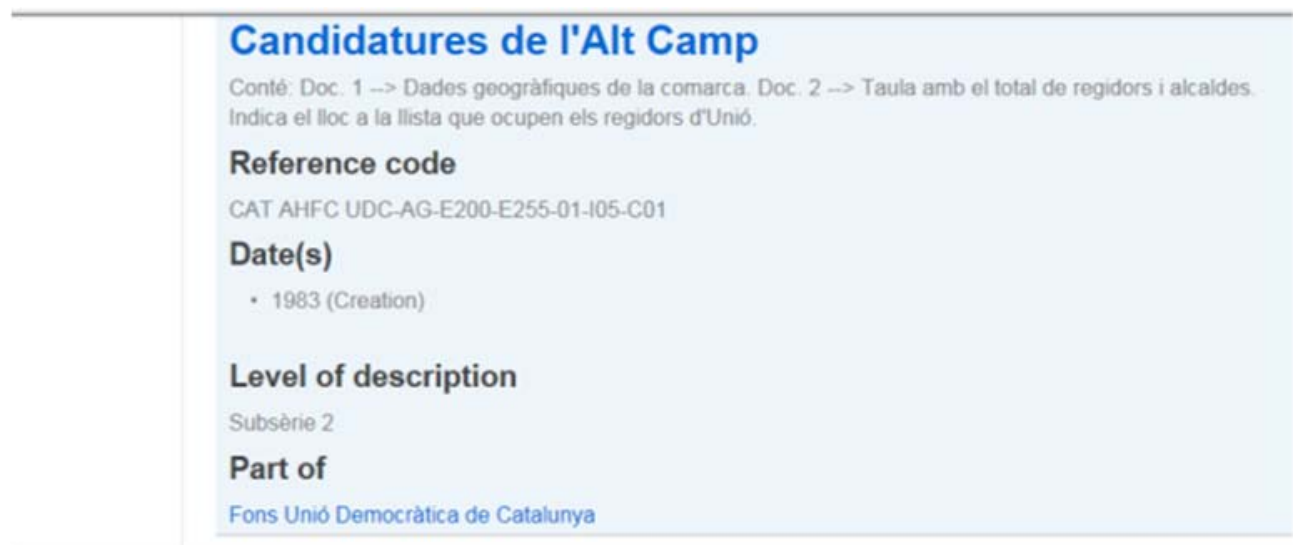

Figura 4:Subdivisions orgàniques: "|05" (Intercomarcal de Tarragona) $i$ "C01" (comarcal de l'Alt Camp)

Permetria contemplar com a alternativa donar un tractament diferenciat en qualitat de subfons o bé un canvi de plantejament en el quadre de classificació a orgànic: en el supòsit de gestió documental descentralitzada amb transferències periòdiques $i$ un arxiu històric a la seu nacional. Facilitaria la gestió de permisos.

\subsection{Possibilitat d'integrar diversos fons.}

El sistema permet introduir fons i col·leccions diferents d'un mateix Arxiu. Els fons personals, en els arxius politics, ocupen un lloc rellevant. 
Recent changes Alphabetic

Browse Archival description

\begin{tabular}{|lll|}
\hline Title & Archival institution & Updated - \\
\hline Fons Llibert Cuatrecasas i Membrado & AHFC & January 26, 2016 9:55 AM \\
\hline Fons Josep Badies i Agusti & AHFC & January 25, 2016 9:49 AM \\
\hline Fons Guadalupe Golobardes i Marti & AHFC & January 20, 2016 8:38 AM \\
\hline Fons Francesc Miralles i Mestre Draft & AHFC & January 20, 2016 8:09 AM \\
\hline Fons Joan Vallvé Ribera Draft & AHFC & January 3, 2016 4:57 AM \\
\hline Fons Ramón Martínez Callén Draft & AHFC & December 11, 2015 6:17 AM \\
\hline Fons Oriol Badia i Tobella Draft & AHFC & June 12, 2015 9:30 AM \\
\hline Fons Unió Democràtica de Catalunya Draft & AHFC & April 6, 2015 10:38 AM \\
\hline Fons de prova A Draft & & February 24, 2015 5:31 PM \\
\hline Fons Joan Baptista Roca i Caball Draft & AHFC & February 6, 2015 8:09 AM \\
\hline
\end{tabular}

Figura 5: Llistat de fons de l'AHFC

Durant el procés d'organització convé, per una banda, separar la documentació personal vinculada a la política de la que forma part de la vida de l'organització. En aquest sentit, la documentació seriada generada pels òrgans directius, tals com actes, s'han incorporar a l'arxiu central a l'igual que, per exemple, el text de les ponències que ens mancaven per a completar el fons (registrant la seva procedència, és clar).

Per altra banda, es fa difícil de vegades diferenciar la documentació privada de la pública: a l'AHFC, només s'han acceptat i es conserva documentació sobre política. És a dir, la documentació generada per la seva militància, molt útil per a conèixer la biografia dels personatges $i$ com s'ha anat formant l'esperit polític i desenvolupant la seva ideologia i tendència en la seva vinculació amb el Partit. Destaquem també la correspondència paral·lela de polítics fundadors i influents dins del Partit i documents solts que assoleixen molta importància per ser únics, antics i per exemple de l'època franquista, període en què la seva activitat transcorria en la clandestinitat. Per altra banda, hi ha la documentació dels qui s'hi han dedicat professionalment exercint tasques diverses en l'exercici de càrrecs a diferent escala dins del Partit i també la d'aquells que han exercit tasques de govern en diverses jurisdiccions de la vida pública a ajuntaments, Generalitat de Catalunya, Parlament de Catalunya, Congrés i Senat espanyols i al Parlament Europeu. La documentació pública forma part dels arxius institucionals respectius si bé sempre hi ha una part, sovint més particular, secundària i mínima que hi està relacionada, que resta a mans 
particulars com per exemple la dels grups parlamentaris i de la qual n'hi pot haver més encara en mans particulars ${ }^{4}$.

- nuuıviny ırcuivo
- Archival institutions
- Functions
- Subjects
- Places
- Digital objects

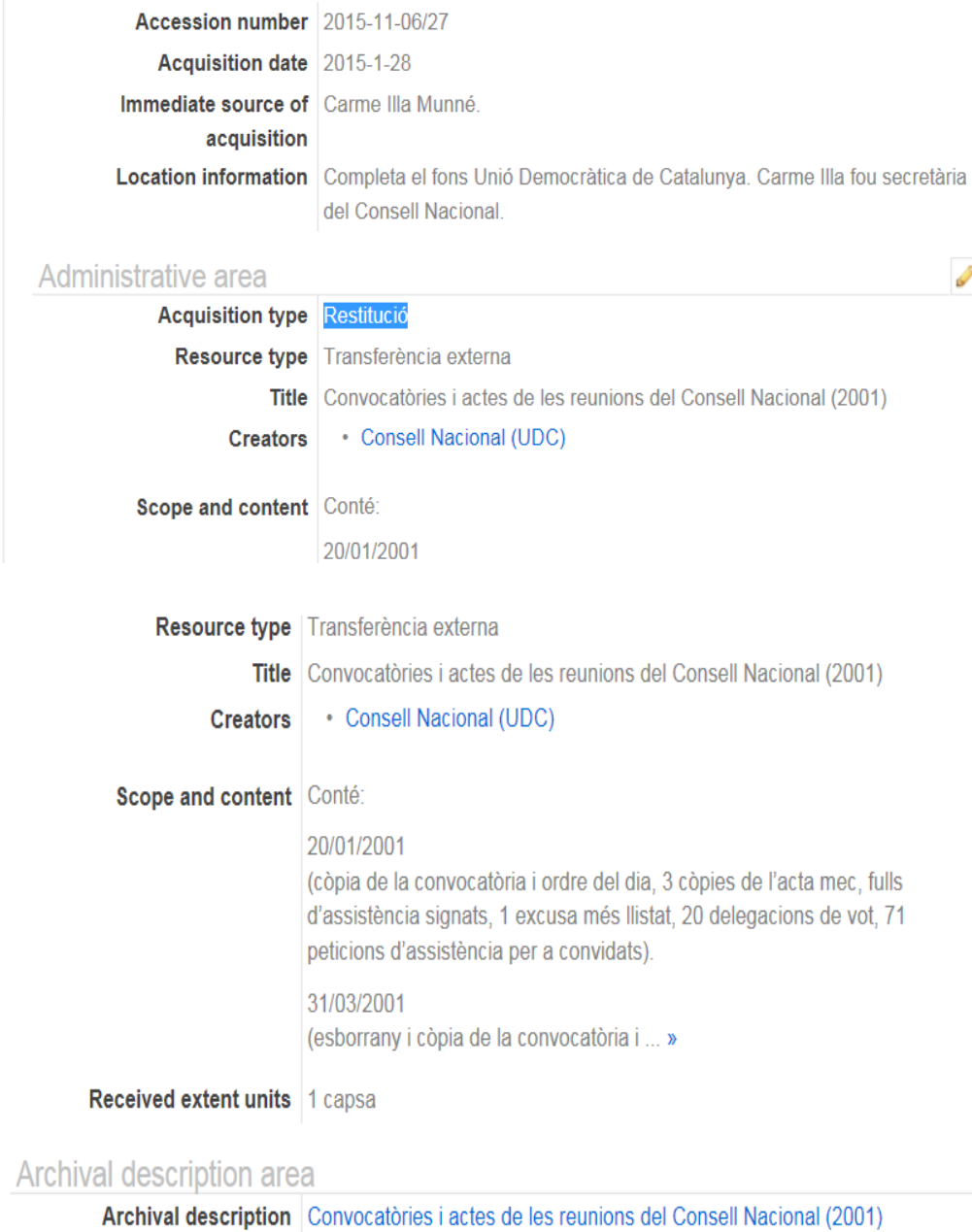

Figura 6: Fitxes de transferència d'un ingrés (fons personal): restitució al fons corporatiu.
$2016-07-24 / 57$

\section{6-07-24/57}

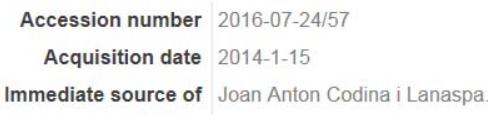

${ }^{4} \mathrm{La}$ documentació dels grups parlamentaris no es conserva a l'arxiu del Parlament de Catalunya. 
Scope and content Conté

- Ordre del dia i horaris del V Congrés d'Unió Democràtica de Catalunya

(Barcelona, 12-13 juny 1976)

- "Funcionament del Congrés d'Unió Democràtica de Catalunya" (1 díptic + fotocòpia amb alguna anotació).

- Extracte de la publicació de la notícia al butlletí corporatiu (2

exemplars).

- Recull de premsa de "La Vanguardia"

- Comunicat $n^{\circ} 1$ 01/10/1977.

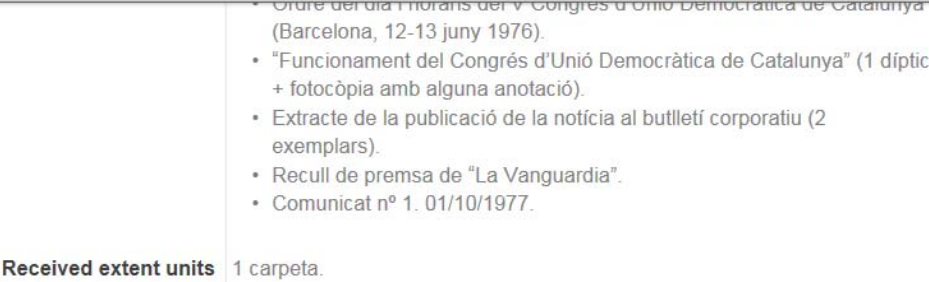

Archival description area

Archival description Reglaments del Congrés Nacional (1976)

Figura 7: Fitxa de transferència d'un ingrés de complement (fons personal).

A diferència de la documentació corporativa, els fons personals que sumen uns vint aproximadament, han estat organitzats en base a un criteri mixt: orgànico-funcional: orgànicament en funció dels càrrecs ocupats $\mathrm{O}$ productor específic de la documentació i, en part, sota el títols de sèries genèriques equiparables al quadre de classificació d’Unió (per exemple: Agenda, Congressos, Manifestos, etc.).
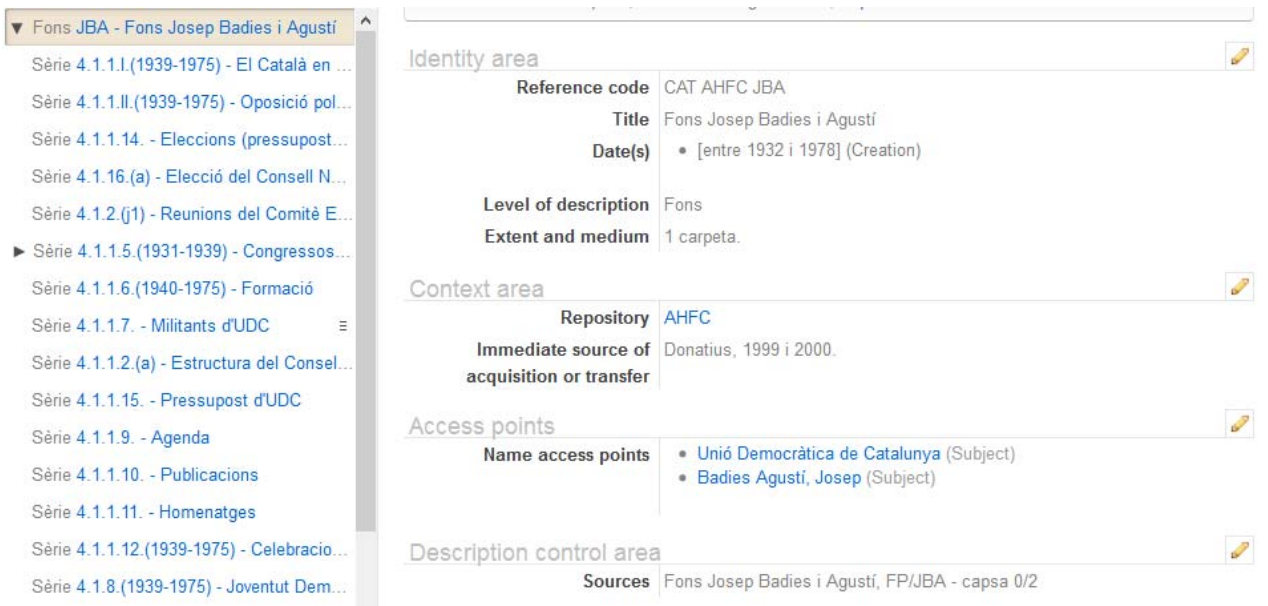

Figura 8: Exemple de sèries del quadre de classificació de fons personal equiparables al quadre d'UDC 

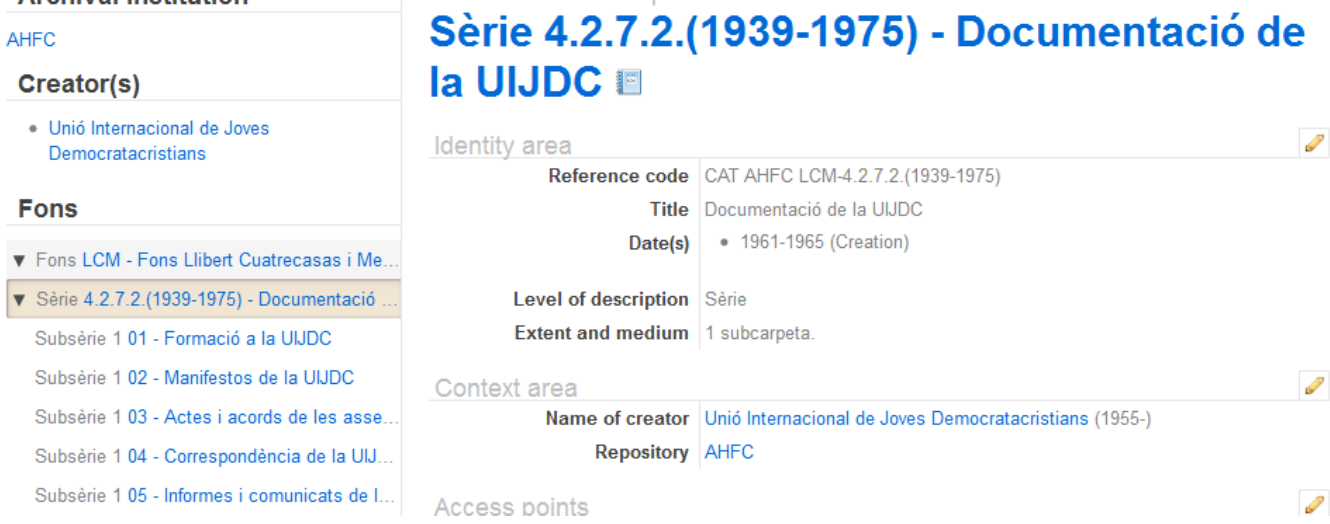

Figura 9: Exemple de quadre de classificació orgànic de fons personal (Llibert Cuatrecasas)

\subsection{Flexibilitat i transversalitat.}

A iCA-Atom, les descripcions de tots els arxius i col-leccions estan relacionades entre si a partir de dos recursos integrats. Són una mostra de flexibilitat:

6.4.1 Índex de funcions: El llistat alfabètic és únic i, per tant, cal explicitar dues casuístiques. En primer lloc, pel que fa a la documentació que pertany a un mateix fons $\mathrm{i}$ en relació a les de les fundacions, equips especialitzats i unitats orgàniques jeràrquiques i facetades (grups de treball en diferents àmbits d'especialització), dins del partit per mitjà d'un conjunt preposicional al final de la frase.

\begin{tabular}{|l|l|}
\hline Actes de protocol de la FLVA & Tasca \\
\hline Actes formatius per a militants d'UDC & Activitat \\
\hline Actes i acords de les reunions de la UIJDC - LCM & Ȧmbitsecció \\
\hline Actes provisionals de la Junta de Portaveus & Tasca \\
\hline
\end{tabular}

Figura 10: Exemple del llistat integrat de funcions.

En segon lloc, les sèries dels diferents fons o col·leccions es poden vincular per mitjà dels índexs i també de les relacions. La documentació que pertany a sèries paral·leles quedaran sempre situades consecutivament a la llista alfabètica: ens referim a les de quadre general corporatiu i les de cadascun dels fons personals. Altrament, hi ha dues solucions possibles per agrupar-les a partir de les sigles formades per les tres lletres en majúscula del nom del productor en el cas dels fons personals. Es poden afegir a l'inici per tal de 
poder recuperar-les juntes (si bé es pot consultar de manera individualitzada el quadre de classificació particular pel fons personal en concret) o bé anotar-les al final per tal que, d'aquesta manera, la documentació corresponent al mateix àmbit d'activitat es puguin recuperar visualitzar juntes independentment de la distribució de fons.

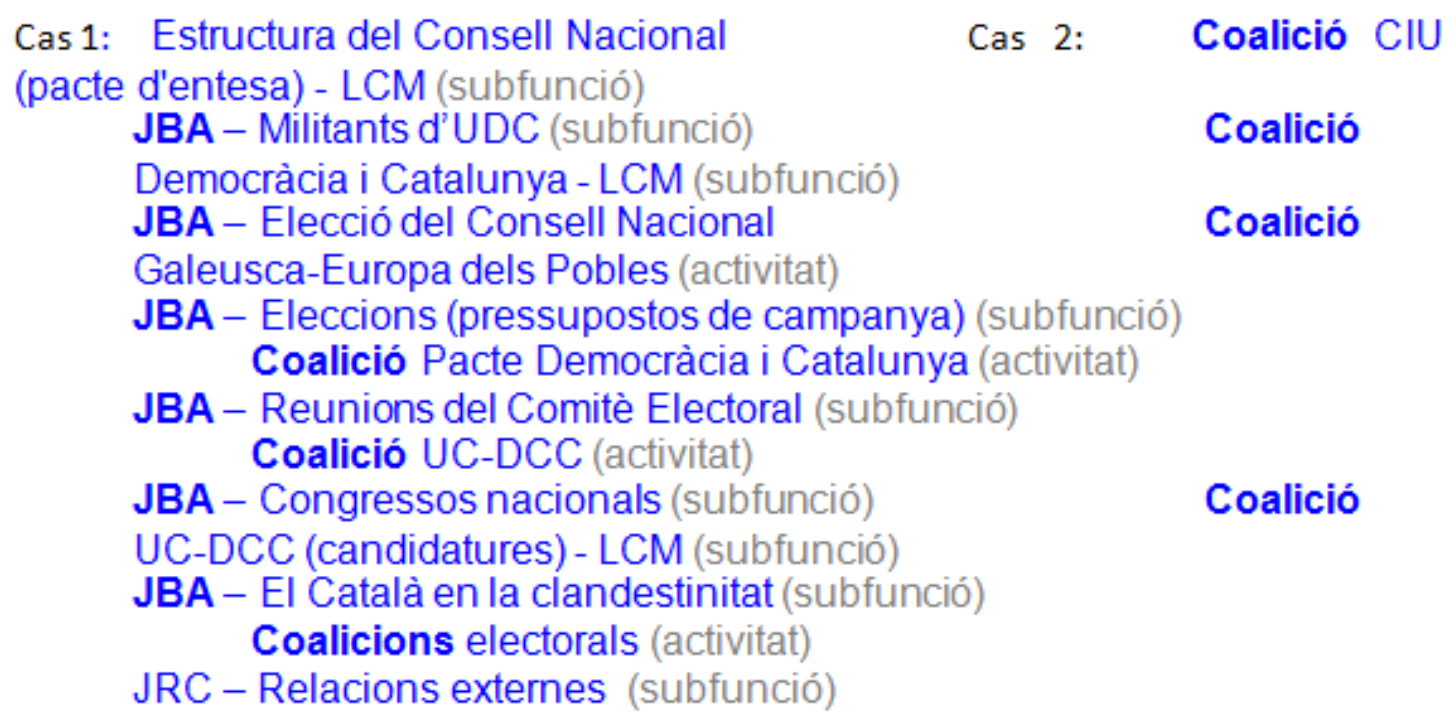

Figura 11: Extractes de l'index de funcions.

A un altre nivell, la xarxa de relacions s'estableix a la notícia de cada funció on, en el moment de donar-la d'alta es poden registrar dades que permeten identificar-ne les característiques i procedència dins del fons i col·lecció del qual forma part: nom, codi de classificació, productor, referent corporatiu) i alhora establir els vincles amb altres sèries sota tres criteris: cronològic (consecutives: històric de funcions), jeràrquic (al nivell immediatament superior) i associatiu (altres criteris). És el cas, per exemple, les sèries acumulatives com són les actes dels diferents òrgans directius, on s'informa, debat $\mathrm{i}$ vota sovint sobre fets diversos que impliquen diferents unitats orgàniques $i$ càrrecs representatius. També les sèries paral·leles a les quals ja ens hem referit: 


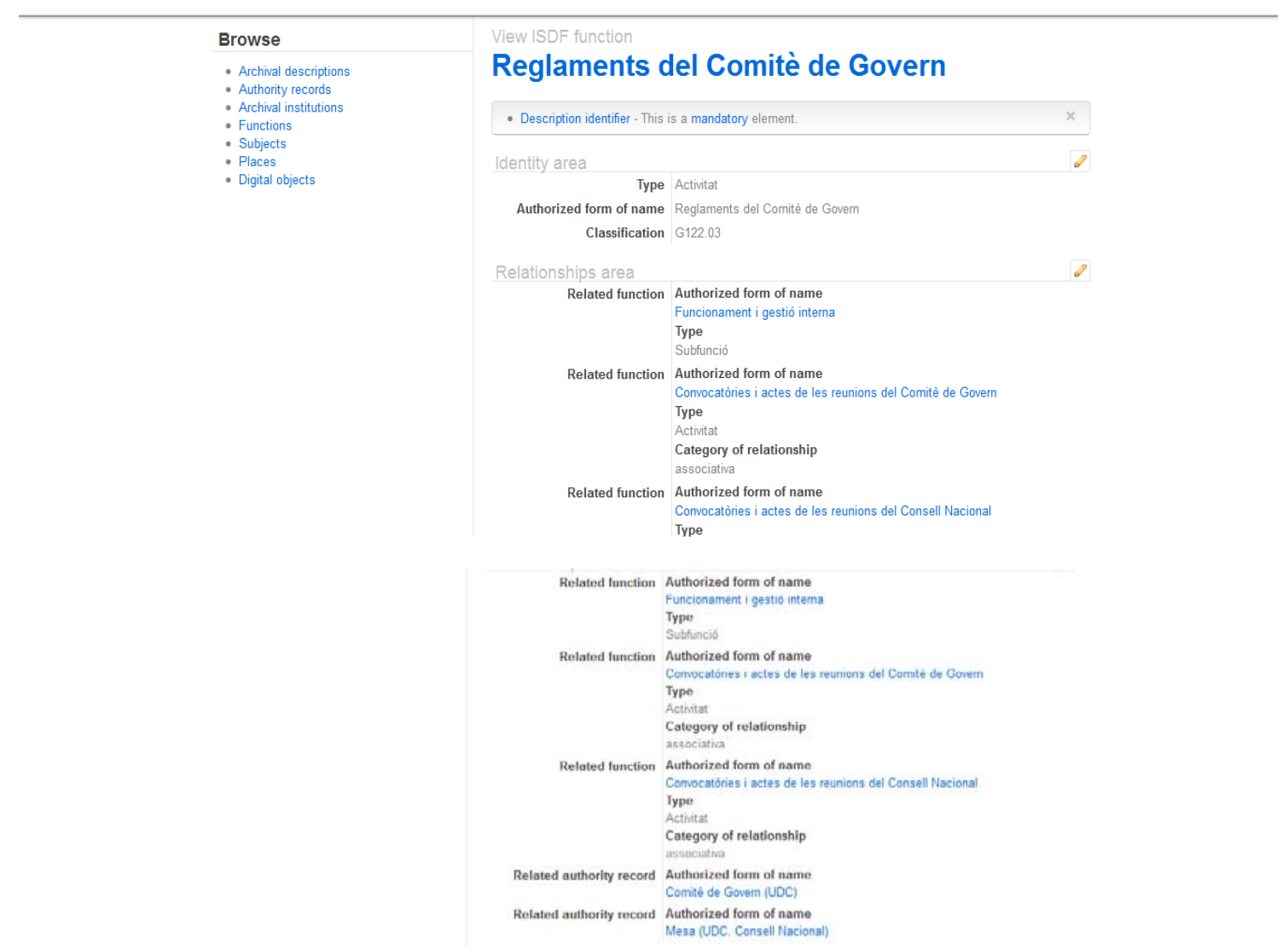

$\underline{\text { Aliances de partit per la governabilitat }}$

Identity area

Related function

Type

Subfunció

Type

Category of relationship

Àmbit/secció

associativa

Authorized form of name of relationship

Aliances de partit per la governabilitat [196-]

Classification

Related function

E150

form of name

electorals

Context area

Type

hierarchical
Authorized form of name

ACTIVITAT LEGISLATIVA

Type

Dates

Subfunció

Category of relationship

Authorized

Related function

Coalicions

\section{Authorized form of name}




\section{Aliances entre partits en eleccions autonòmiques \\ Activitat \\ Category of relationship \\ Legislation
associativa \\ Activitat \\ (Estatuts 2005, Cap. IV, art. 43): \\ Related function \\ "Les relacions amb altres forces polítiques hierarchical \\ Authorized form of name \\ ialiances electorals han de ser aprovades pel Related function \\ Reculls de premsa sobre pactes entre \\ Type \\ $\mathrm{CN}$ i pel Congrés quan afectin al a sevaAuthorized form of name partits polítics \\ sobirania". \\ Possibles aliances de partits - LCM \\ Type \\ Relationships area \\ Activitat \\ relationship \\ Category of \\ associativa \\ Figura 12: Exemples de sèries relacionades $i$ un de la vinculació del Fons d'UDC $i$ el fons personal LCM. \\ 6.4.2 Índex de noms: El sistema permet crear registres d'autoritat seguint els estàndards internacionals: la normativa ISAAR (CPF) distingint i especialment útil per a noms personals, corporatius I de família ${ }^{5}$. En aquest cas, també hi ha una doble via per accedir-hi: el llistat alfabètic i, a partir de qualsevol conjunt resultant d'una cerca, pel camp de productor i descriptors nominals (estan enllaçats). Amb les referències creuades, s'ha pot relacionar els encapçalaments de nom dels polítics amb els encapçalaments de les unitats orgàniques del partit, jurisdiccions en el cas de càrrecs públics i/o entitats de tipologia diversa tenint la possibilitat d'indicar els anys que els han ocupat el càrrec $i$, en text natural, qualsevol menció aclarativa així com la font $o$ recursos relacionats:}

\footnotetext{
${ }^{5} E n$ aquest cas, els de família no s'han utilitzat donat que l'AHFC no té documentació personal ni familiar, per bé que sí que hi ha membres del partit que poden estar emparentats. Es pot anotar dades biogràfiques.
} 


\begin{tabular}{|c|c|c|c|}
\hline \multicolumn{4}{|c|}{$\nabla$ Relationships area } \\
\hline \multicolumn{4}{|c|}{ Related corporate bodies, persons or families } \\
\hline Name & Type & Dates & Description \\
\hline \multicolumn{4}{|l|}{ Add new } \\
\hline \multicolumn{4}{|c|}{ Related resources } \\
\hline Title & & Relationship & Dates \\
\hline
\end{tabular}

- Authority records

- Archival institutions

- Functions

- Subjects

- Places

- Digital objects
Browse Authority record

\begin{tabular}{|l|l|}
\hline Name - & Type \\
\hline Acció Catalana & Corporate body \\
\hline Adroher i Santamaria, Miquel & Person \\
\hline AG \& S. Aragay & Corporate body \\
\hline Agència Tributària Catalana & Corporate body \\
\hline Águila de Torres, Diego del & Person \\
\hline
\end{tabular}

Figura 13: Llistat alfabètic d'autors.

En el registre, un cop creat s'hi vincularan totes les descripcions on hi aparegui com a matèria i com a nom, respectivament:

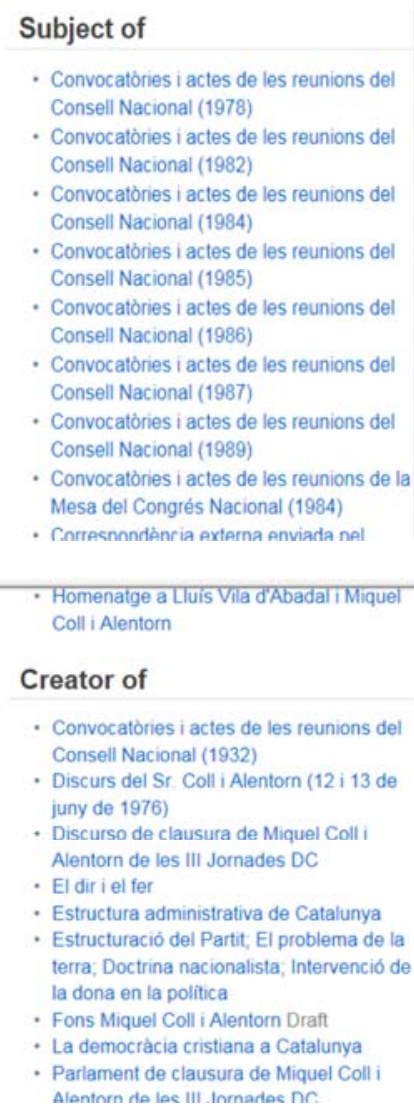

- Convocatóries i actes de les reunions del Consell Nacional (1978)

- Convocatòries i actes de les reunions del Consell Nacional (1982)

- Convocatóries i actes de les reunions del Consell Nacional (1984)

- Convocatóries i actes de les reunions del Consell Nacional (1985)

- Convocatóries i actes de les reunions del Consell Nacional (1986)

- Convocatories i actes de les reunions del Consell Nacional (1987)

- Convocatóries i actes de les reunions del Consell Nacional (1989)

- Convocatories i actes de les reunions de la Mesa del Congrés Nacional (1984)

- C.nrrasnnndènria externa anviada nel

- Homenatge a Lluis Vila d'Abadal i Miquel Coll i Alentorn

\section{Creator of}

- Convocatóries i actes de les reunions del Consell Nacional (1932)

- Discurs del Sr. Coll i Alentorn (12 i 13 de juny de 1976)

- Discurso de clausura de Miquel Colli

Alentorn de les III Jornades DC

- El dir i el fer

- Estructura administrativa de Catalunya

- Estructuració del Partit, El problema de la

terra; Doctrina nacionalista; Intervenció de la dona en la politica

- Fons Miquel Coll i Alentorn Draft

- La democràcia cristiana a Catalunya

- Parlament de clausura de Miquel Coll i Alentorn de les III Innaries ne

\section{View authority record}

\section{Coll i Alentorn, Miquel}

- Description identifier - This is a mandatory element

Identity area

Type of entity Person

Authorized form of name Coll i Alentorn, Miquel

Other form(s) of name $\cdot$ Coll, Miquel

Description area

Dates of existence 1904-1990

History "Historiador i politic. Fou un dels organitzadors de Palestra i dirigent de la joventut d'Acció Catalana Republicana (1931-32). El 1932 ingressá a la

$\begin{array}{ll}\text { Related entity } & \text { Congrés dels Diputals } \\ & \text { Consell Català del Moviment Europeu } \\ \text { Category of the relationship } \\ \text { hierarchical } \\ \text { Dates of the relationship } \\ \text { [ca. 1976] } \\ \text { Description of relationship } \\ \text { Miquel Coll fou president del Consell Català del Moviment Europeu }\end{array}$

Figura 14: Fitxa d'autoritat de nom personal amb una part de les entitats relacionades.

Cal tenir en compte que els termes relacionats sempre han d'haver estat prèviament introduïts a la base de dades i es pot indicar el tipus de vincle: 


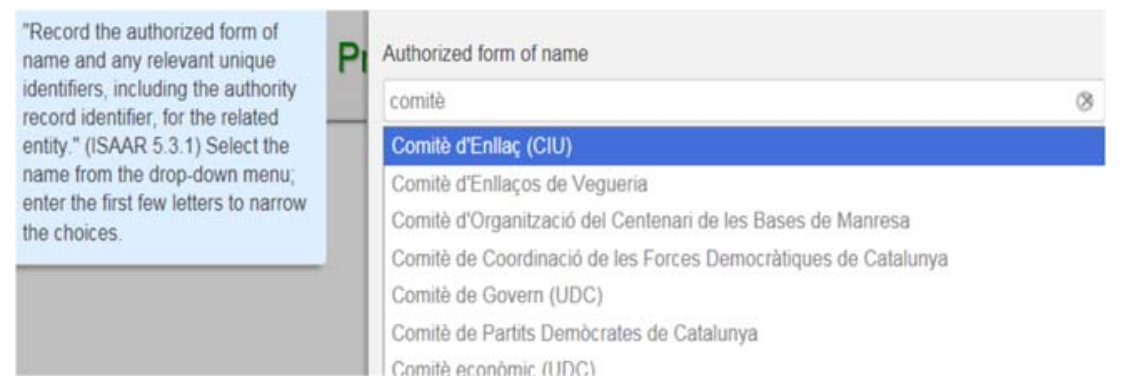

Per procedència, es pot cercar per l'índex de noms, per la llista de fons (navegació en el propi quadre de classificació), per l'índex de funcions i per nom dels donants al mòdul de transferències.

En els registres d'autoritat de nom d'aquells militants o polítics dels quals tinguem el fons personal o col-leccions, es podrà indicar a l'" Àrea de recursos relacionats" un vincle a la fitxa del fons personal (també hauria d'estar prèviament introduït al sistema) indicant com a "Naturalesa de la relaciô": creació o col·lecció.

\subsection{Catàleg integrat de recursos.}

En la versió utilitzada en l'aplicatiu, la 1.2, no està ben resolt el sistema de menús per a indicar la tipologia documental en les descripcions arxivístiques. Si bé hi ha dues taxonomies on es poden parametritzar els camps tant de tipologia segons el mitjà com de forma, no estan ben resoltes sense desenvolupament del programari i no s'han pogut implementar com a camp informatiu a la plantilla: 


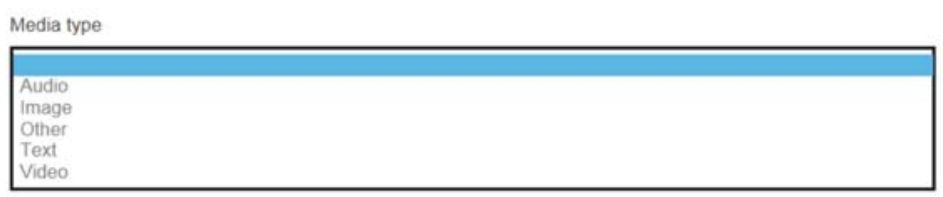

No obstant, s'han definit diverses pràctiques per adaptar la base de dades a les necessitats:

6.5.1 Opció de catàleg integrat indicant la informació al text de la descripció. Per aquest criteri només seran recuperables per paraula clau i, donat que podrà variar el nombre (singular o plural) hi haurà silenci documental:

o al camp "Volum" de descripció física les unitats i formats separats per una coma.

o a l'inici del camp "Títol".

o com a part de la redacció al camp de resum o "contingut".

La cerca avançada facilita la recuperació per paraula clau limitada a un o més camps de la descripció alhora amb els operadors booleans ("OR", "AND" i "NOT").

P.ex. 1 fotografia $(b / n)$.

Fotografia amb els membres de la llista electoral.

6.5.2 Opció de catàleg integrat indicant com a descriptor de matèria (en aquest cas de gènere) en singular. Es podran recuperar els documents per paraula clau però de manera més exacta per l'índex alfabètic corresponent. Es parteix d'un llistat predefinit normalitzat.

P.ex. carpeta personalitzada, samarreta, fotografia, claner, bossa, etc.

6.5.3 Opció de considerar els documents pel suport i crear, d'inici, diversos subfons. En aquest punt o es descriuria en cadascun els documents en bloc i a part (paral·lelament reproduint les sèries que calgui del quadre de classificació del fons) amb sèries que comencin per "Fotografies (nom de la sèrie)" que posteriorment es relacionin en l'íindex de funcions. O bé, com a alternativa, es pot incloure una descripció de conjunt d'acord amb el nivell per a cadascun dels subfons i indicar com a recurs associat un enllaç al resultat de la cerca per tipologia documental com a matèria, per exemple. 


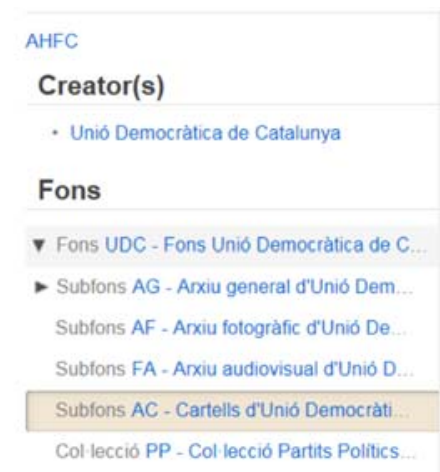

\section{Subfons AC - Cartells d'Unió Democràtica de Catalunya (Draft)}

Identity area

Context area

Content and structure area

Conditions of access and use area

En una següent fase hi havia prevista la implementació del catàleg bibliogràfic de recursos impresos sota la categoria de "Col·lecció" al mateix nivell que els "Fons" i amb el centre de documentació donat d'alta al sistema com a nova institució arxivística. Així es pot donar una perspectiva global del projecte inicial. Ens referim a:

\section{Biblioteca}

1.1.) Obres de referència.

1.2.) Monografies i colleccions.

1.3.) Dossier temàtic.

\section{Hemeroteca}

2.1.) En base al llistat en Excel.

2.2.) En el moment no hi havia cap subscripció donada d'alta però calia actualitzar-lo afegint-hi els número ingressats posteriorment al 2006 juntament amb altres números solts antics.

Les publicacions pròpies o dels membres de l'organització es consideraran alhora com a part de l'Arxiu en tant que algunes són producte directe de la seva activitat: estatuts, ponències, reglaments, etc. Per altra banda, pel que fa al material que prové de les biblioteques personals o privades donades pels polítics $\mathrm{i}$ militants, es farà constar la seva procedència en una nota. La informació que les vincula es marquen a continuació amb un asterisc.

Les descripcions s'estructuren seguint les àrees de la NODAC (Bernal, A., Magrinyà, A. i Planes, R. ed., 2007), adaptació de la norma per arxius promoguda pel Consell Internacional d'Arxius (International Council on Archives, 2001): 


\begin{tabular}{ll}
\hline Àrea d'identitat & Codi de referència, Nivell \\
& de descripció (document), \\
& tipus de document, Títol, \\
& Data, Volum (descripció \\
& física).
\end{tabular}

Àrea de context

Dades sobre l'ingrés (procedència: donant 0 col·leccio)*.

Àrea de contingut i Abast i contingut (nota de estructura conté o sumari).

Àrea de condicions d'accés i Llengües i escriptures dels ús documents (idioma/es); Característiques físiques i requeriments tècnics (suports òptics $i$ documents electrònics).

Àrea de documentació Permet establir enllaços a relacionada altres descripcions a partir de la funció, registres d'autoritat de nom (productor)* o a recursos $^{*}$ externs.

Àrea de notes Menció de publicació (publicacions); menció de drets i qualsevol altra dada rellevant.

Punts d'accés

Descriptors onomàstics (autor $i$ altres mencions de responsabilitats); geogràfics i de matèries (descriptors). 


\section{Més enllà de la descripció}

A més de la distribució, descripció i relació ICA-AtoM permet plantejar múltiples possibilitats: per exemple, l'opció de recursos. Destaquem prendre com a consideració la possibilitat depenjar o enllaçar documents des de la fitxa de fons corporatiu, personal o col·lecció:

a) Fons complementaris: Pot contenir: a1) Documents o enllaços a Inventaris o web d'arxius o altres centres dipositaris que custodiïn documentació de fons disgregats o que ampliarien informació sobre els membres o activitat de l'entitat privada d'origen. Es registraria a l"'A Area de documentació relacionada" de la fitxa de fons o nivell corresponent amb un resum breu i un enllaç, si és el cas, o bé adjuntant un fitxer. Si les reproduccions es descriuen a part es pot indicant-ne, en aquesta àrea, al camp corresponent la font.

Són arxius complementaris: el del Parlament de Catalunya (activitat dels grups parlamentaris si bé és escassa pel que fa als partits polítics), Archivo del Congreso de los Diputados i Senado espanyols, l'Arxiu de Convergència Democràtica de Catalunya (anterior a 2015 pel que fa a l'activitat de la coalició i federació), Arxiu de la Generalitat de Catalunya (anys i carteres d'activitat dels consellers i directors generals en anys que ocupaven els càrrecs), fons personals de militants a l'Arxiu Nacional de Catalunya o Pavelló de la República de la Universitat de Barcelona, etc.

b) Blocs personals de politics relacionats amb la seva vessant política. S'enllaçaria des de la fitxa del fons personal en qüestió, des de l'" Área de descripció" del registres d'autoritat de nom al camp "Funcions, ocupacions i activitats" (única manera de relació enc cas que no tinguem documentació com a fons personal) o bé, en darrer terme, com a "Bibliografia" a l'Àrea de documentació relacionada.

c) Versió web: Donat que el sistema permet la seva consulta web es pot seleccionar quins camps poden format part de la interfície de cerca, decidir si es vol utilitzar com a base de dades interna i/o parcialment decidir què es posa -si així es decideix- de consulta pública. En un partit polític esdevé molt important controlar l'accés a la documentació en curs o que no ha esdevingut històrica. L'adaptació d'ICA-AtoM a la naturalesa dels documents d'arxiu permet assignar diferents nivells d'accés: 


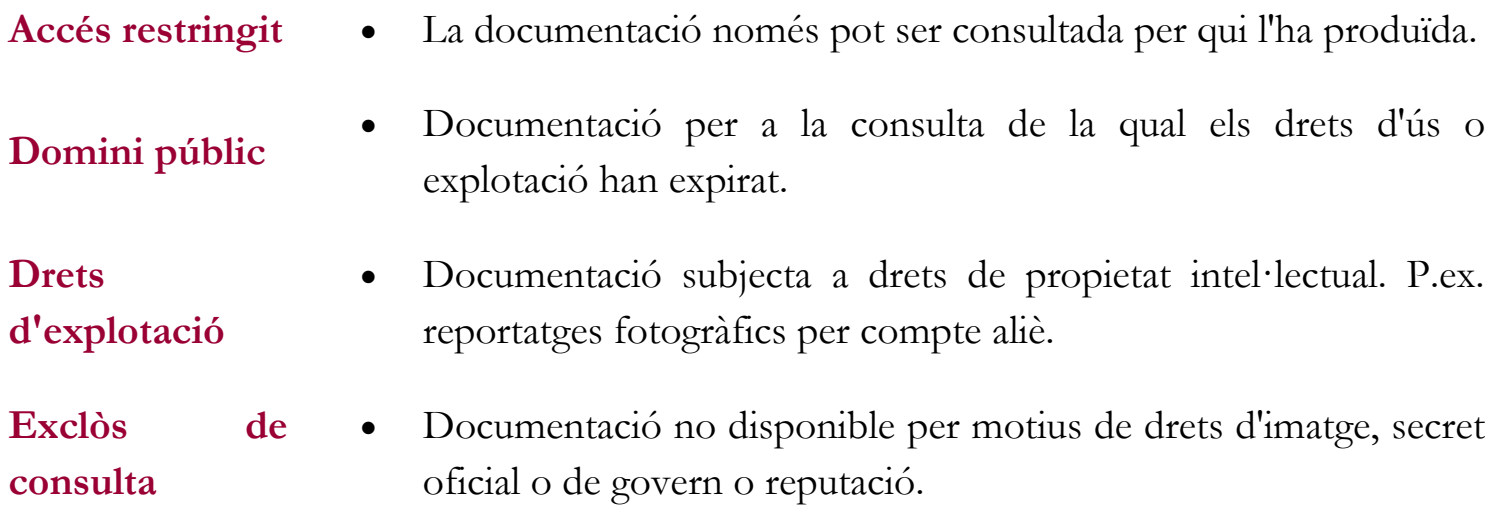

Qualsevol altra dada es pot consignar al camp de text lliure de "Notes".

Actualment, amb l'ingrés de tots els fons i col-leccions de l'Arxiu Històric Ferran Camps a l'Arxiu Nacional de Catalunya on es seguiran els protocols habituals i adaptació a les eines informàtiques pròpies de tractament documental el fons continuarà a mig termini estant a disposició de tots els investigadors. Esperem que gràcies a la comunitat virtual en les successives versions el programari segueixi aportant solucions per a tot tipus d'arxius.

\section{Bibliografia}

ALCARAZ MARTÍNEZ, R. et al., Lluís, 2013. Mapa de software libre en España [en línia]. Dins: XIII Jornadas Españolas de Documentación FESABID'13.Toledo: FESABID, 24 i 25 maig [Consulta: 12 maig 2018]. Disponible a: http:// fesabid.org/documentos/fesabid13-actas.pdf .

ARTEFACTUAL SYSTEMS, 2013. AtoM (Acces to Memory) [en línia]. New Westminster: Artefactual, 2017 [Consulta: 12 maig 2018]. Disponible a: https://www.accesstomemory.org/es/.

ATUG-I, 2013. Archivists'Toolkit for archivists by archivists[en línia]. [Estats Units]: Andrew W. Mellon Foundation; University of California San Diego Libraries, 2013 [Consulta: 12 maig 2018]. Disponible a: http://www.archiviststoolkit.org/.

BARBERÀ I ARESTÉ, Óscar, 2010. Unió Democràtica de Catalunya (1931-2003): evolució política i organitzativa. Bellaterra: UAB. Servei de Publicacions.

BERNAL, A., MAGRINYÀ, A. I PLANES, R. (ed.), 2007. Norma de Descripció Arxivistica de Catalunya (NODAC). Barcelona: Generalitat de Catalunya. Departament de Cultura i Mitjans de Comunicació [consulta: 12 maig 2018]. Disponible 
http://www20.gencat.cat/docs/CulturaDepartament/Cultura/Temes/Arxius $\angle$ Banners/arxius/NODACpublicada.pdf .

BIARGE, B., 2014. ICA-AtoM: manual para arcbiveros: version 02. Barcelona: Vidimus [Consulta: 12 maig 2018]. Disponible a: https://issuu.com/rodrigoalvarezportugal/docs/ica atom manual v02 .

BIBLIOTECA DE CATALUNYA, 2009. Llista d'Encapsalaments de Matèria en Català (LEMAC) [en línia]. Barcelona: Biblioteca de Catalunya, 2018. [Consulta: 12 maig 2018]. Disponible a: http://www.bnc.cat/lemac/.

ESCOLA D’ARXIVÍSTICA I GESTIÓ DE DOCUMENTS DE CATALUNYA, SERVICIO MÓVIL, 2013. MOLĖCULA Gestió integral de l'Arxiu [en línia]. Coruña: SM Tecnología [Consulta: 12 maig 2018]. Disponible a: http://www.molecula-gia.com/ i demo disponible a: http://demo.moleculagia.com/index.php/.

INTERNATIONAL COUNCIL ON ARCHIVES, 2001. ISAD (G): Norma Internacional General de Descripció Arxivística. 2a edició. Barcelona: Associació d'Arxivers de Catalunya; Generalitat de Catalunya. Departament de Cultura [Consulta: 12 maig 2018]. Disponible a: http://cultura.gencat.cat/web/.content/dgpc/arxius despublicada/norma de descripcio arxivistica de catalunya/arxius/isad2 catala.pdf.

LENCINAS, V. et al., 2015. Ensalada de Metadatos: experiencias en torno a la construccion de metadatos de un archivo para astrónomos. Argentina: Biblioteca Nacional Argentina [Consulta: 12 maig 2018]. Disponible a: https://www.bn.gov.ar/resources/conferences/pdfs/lencinasv-mateoresnatalonif-fabbrod-quintanillam-ponencia.pdf.

LÓPEZ JIMÉNEZ, M. A., 2013. Propuesta para la automatización del Archivo de la Palabra patrimonio cultural inmaterial de los pueblos originarios con Open Source. Mèxic, Escuela Nacional de Biblioteconomía y Archivonomía de México (tesi de llicenciatura) [Consulta: 12 maig 2018]. Disponible a: http://eprints.rclis.org/24622/.

LYRASIS, 2017. ArchiveSpace [en línea]. Atlanta: Lyrasis, 2018 [Consulta: 12 maig 2018]. Disponible a: http://archivesspace.org/.

MACÍAS, A., 2013. Gestión documental con software libre: Nuxeo, Alfresco y Athento [en línia]. Dins: Grup de Treball de Programari Lliure per als Professionals de la Informació (bloc). Barcelona: COBDC, 2018 [Consulta: 12 maig 2018]. Disponible a: http://www.cobdc.net/programarilliure/gestion-documentalsoftware-libre-nuxeo-alfresco-athento/.

MCCRORY, A. I RUSSELL, B. M., 2005. Crosswalking EAD: collaboration in Archival Description [en línia]. Information Technology and Libraries, Vol 24 (3), p. 
99-106. [Consulta: 12 maig 2018]. Disponible a: https://ejournals.bc.edu/ojs/index.php/ital/article/view/3371.

MONTES, S. i VICENTE HERNÁNDEZ, L., 2009. La memoria en abierto: la implementación del software Archon para la gestión del archivo digital del Ateneu Barcelonés [en línea]. Dins: Interinformación : XI Jornadas Españolas de Documentación. Zaragoza, 20-22 maig, p. 267-274. Logroño: Fundación DialNet, 2018 [Consulta el 12 de maig de 2018]. Disponible a: https://dialnet.unirioja.es/servlet/articulo?codigo $=2973218$.

MOREIRO, J. A. et al., 2012. Evaluación de software libre para la gestión de archivos administrativos [en línia]. El Profesional de la Información, c. 20 (2), p. 206-213 [Consulta: 12 maig 2018]. Disponible a: http://eprints.rclis.org/17161/1/206-213.pdf .

RUSSO-GALlO, P., RODRÍGUEZ-GAIRÍN, J.-M. i SULÉ-DUESA, A., 2008. Laboratorio virtual de software libre para bibliotecas [en línia]. El Profesional de la Información, v. 17, n. 1, p. 71-77 [Consulta: 12 maig 2018]. Disponible a: http://www.elprofesionaldelainformacion.com/contenidos/2008/enero/08.p df.

TEMESIO, S., 2014. Aplicaciones informáticas de software libre en archivos: una visión integradora [en línia]. Dins: VI Encuentro Latinoamericano de Bibliotecarios, Archivistas y Museólogos. 24-26 setembre. Medellín, Colombia: EBAM. [Consulta: 12 maig 2018]. Disponible a: http://eprints.rclis.org/24211/2/SILVANA TEMESIO PONENCIA EBA M2014.pdf.

UNESCO, 1977. Tesauro de la Unesco [en línia]. París: Unesco, 2018 [Consulta: 12 maig 2018]. Disponible a: http://databases.unesco.org/thessp/.

UNIVERSITY OF ILLINOIS, 2013. ARCHON: the Simple Archival Information System [en línia]. [Estats Units]: University of Illinois, 2014 [Consulta: 12 maig 2018]. Disponible a: http://www.archon.org/.

ZAPATA CÁRDENAS, C. A., 2001. La automatización de archivos: algunas consideraciones para la estructuración de proyectos informáticos en archivos [en línia]. Revista de la Universidad de la Salle, 23(34), p. 127-135 [Consulta: 12 maig 2018]. Disponible a: http://eprints.rclis.org/9893/1/La Automatizaci\%C3\%B3n de Archivos.pd f. 